\title{
Relationship between fat mass and obesity-associated gene expression and type 2 diabetes mellitus severity
}

\author{
QIULING WANG ${ }^{1 *}$, JINHUAN WANG $^{2 *}$, HAIXIA LIN $^{1}$, XUECHEN HUO ${ }^{3}$, QIAOLING ZHU ${ }^{4}$ and MIN ZHANG ${ }^{5}$ \\ Departments of ${ }^{1}$ Endocrinology, ${ }^{2}$ Health, ${ }^{3}$ Biliary Surgery and ${ }^{4}$ Pharmacy; \\ ${ }^{5}$ Neurological Intensive Care Unit, Yantai Yuhuangding Hospital, Yantai, Shandong 264000, P.R. China
}

Received July 6, 2017; Accepted November 21, 2017

DOI: $10.3892 /$ etm.2018.5752

\begin{abstract}
This study sought to investigate any correlation between fat mass and obesity-associated gene (FTO) expression and the severity of type 2 diabetes mellitus (T2DM). In total 110 patients newly diagnosed with T2DM in the outpatient department of Yantai Yuhuangding Hospital between September 2016 and March 2017 were selected as study subjects and were divided into severe (58 cases) and mild groups (52 cases) according to T2DM severity. Patients in the severe group were followed up for 12 weeks. An additional 60 healthy individuals were selected to serve as the normal control group. Fasting plasma glucose (FPG), fasting insulin (FINs), fasting C-peptide (FCP), glycosylated hemoglobin (HbA1c) and homeostasis model assessment of insulin resistance (HOMA-IR) were examined for every patient in the study. Real-time polymerase chain reaction (RT-PCR) was used to detect FTO messenger ribonucleic acid (mRNA) expression levels in patient peripheral blood lymphocytes. Western blotting was used to detect serum FTO protein expression levels, upon which the correlation between FTO protein levels and all other indices were analyzed. Compared with the normal control group, both T2DM groups showed significantly increased waist circumferences, hip circumferences, body mass indexes (BMIs), blood glucose indexes (FPG, FCP, HbA1c, FINs, HOMA-IR) and FTO mRNA/protein levels $(\mathrm{p}<0.05)$. Additionally, the increases presented by the severe T2DM group were significantly greater than those presented by the mild T2DM group $(p<0.05)$. After 12 weeks of treatment, the severe T2DM group showed decreased BMI, blood glucose index and FTO protein expression $(\mathrm{p}<0.05)$. FTO protein expression in T2DM patients was higher than in healthy controls, with
\end{abstract}

Correspondence to: Dr Min Zhang, Neurological Intensive Care Unit, Yantai Yuhuangding Hospital, 20 Yuhuangdingdong Road, Yantai, Shandong 264000, P.R. China

E-mail: ehd7xr@163.com

*Contributed equally

Key words: FTO, type 2 diabetes mellitus, obesity severe patients showing greater expression levels than mild group patients. FTO expression was positively correlated with BMI, waist circumference, chest circumference, FPG, FCP, HbA1c, FINs and HOMA-IR. Therefore, FTO expression can serve as a marker for the clinical diagnosis and treatment of T2DM.

\section{Introduction}

Obesity and insulin resistance are closely related to metabolic syndrome and other diseases. In particular, obesity is an indicating factor for the pathogenesis of type 2 diabetes mellitus (T2DM) (1). Adipose cells induce insulin resistance and proinflammatory cytokine production (leptin, tumor necrosis factor and interleukin-6) (2), leading to increased fasting blood glucose levels in patients and ultimately inducing T2DM. Ballantyne et al have reported that blood glucose levels and liver insulin sensitivities of T2DM patients can be restored to normal levels after bariatric surgery and at the 10 year mark post-surgery, almost $90 \%$ of patients present no signs of diabetes (3).

Genome-wide association study has shown that the fat-mass and obesity-associated gene (FTO) is significantly associated with the increase of obesity risk in all current determined susceptibility loci to obesity $(4,5)$. FTO is expressed in many metabolic disease-related tissues, including adipose tissues and skeletal muscles $(6,7)$. Evidence provided by increasing number of studies have shown that FTO affects the genetic variation of body mass index (BMI) and obesity risk of people in China, Japan, the Republic of Korea and the Philippines (8). In addition, it has been proved that the association between the FTO gene and obesity can indirectly regulate the risk of T2DM (9). This study focused on the clinical significance of the obesity gene FTO in varying degrees of T2DM, so as to study the value of FTO as a marker for the diagnosis and prognosis of T2DM.

\section{Patients and methods}

General subject information. The study subjects consisted of 110 patients with T2DM received and treated by the outpatient department of the Yantai Yuhuangding Hospital between September 2016 and March 2017. These individuals were separated into mild and severe groups according to disease 
severity. In addition, 60 individuals were selected amongst hospital workers and healthy patients undergoing routine physical examinations as the normal control group (NC group). The study was approved by the Ethics Committee of Yuhuangding Hospital.

Grouping criteria. Mild T2DM group: i) Patients whose glycosylated hemoglobin (HbA1c) was $\leq 8 \%$; ii) patients whose diabetic nephropathy did not reach stage 3 and who showed no kidney injury; iii) patients whose diabetic retinopathy did not reach the proliferative standard. Severe T2DM group: i) Patients whose HbAlc was $>8 \%$; ii) patients whose diabetic nephropathy had reached stage 4 ; iii) patients with proliferative diabetic retinopathy. Patients with acute infections and other chronic diseases (e.g., cancer, chronic obstructive pulmonary disease, asthma, dementia, chronic intestinal disease, psychosis, cirrhosis), as well as pregnant and lactating women, were not included in this study. All subjects in this study provided signed informed consent.

\section{Study methods}

Sample collection. All study subjects were forbidden from drinking and eating for $12 \mathrm{~h}$ prior to examinations, which occurred at 7 a.m. At the examinations: i) Each subject's height, weight, waist and hip circumference were measured, and the BMI [body weight $(\mathrm{kg}) /$ height $^{2}\left(\mathrm{~m}^{2}\right)$ ] was calculated; ii) blood $(2.5 \mathrm{ml})$ (fasting blood sample) was collected from every subject. One sample was placed in a vacuum centrifuge tube for examination of the following T2DM blood glucose indices: Fasting plasma glucose (FPG), fasting C-peptide (FCP), HbAlc and fasting insulin (FINs). Samples in vacuum centrifuge tubes were centrifuged for $15 \mathrm{~min}$ at $912 \mathrm{x} \mathrm{g}$, with the upper layer consisting of the serum taken and stored at $-80^{\circ} \mathrm{C}$. The other sample was stored in an EDTA anticoagulant tube for lymphocyte extraction, which was performed using a human lymphocyte separation reagent kit (TBD, Tianjin, China) with the extracted lymphocytes stored at $-80^{\circ} \mathrm{C}$; and iii) homeostasis model assessment of insulin resistance (HOMA-IR) was calculated according to the following formula: FINS (mmol/l) $x$ FPG $(\mathrm{mmol} / \mathrm{l}) / 22.5$.

The 52 patients in the severe T2DM group were treated with medication based on patient-specific conditions and followed up for 12 weeks. During treatment, patient condition data was regularly collected by a specially assigned person. On the day prior to the end of treatment, whole blood samples were obtained from each patient for testing.

Detection of lymphocyte FTO gene expression by real-time polymerase chain reaction (RT-PCR). TRIzol reagent $(1 \mathrm{ml}$; Invitrogen Life Technologies, Carlsbad, CA, USA) was added into an Eppendorf tube (Eppendorf AG, Hamburg, Germany) containing human lymphocytes and then the tube was incubated at $4^{\circ} \mathrm{C}$ for $30 \mathrm{~min}$. Chloroform $(200 \mu \mathrm{l})$ was added, upon which the sample was mixed and then centrifuged at $12,000 \mathrm{xg}$ for $15 \mathrm{~min}$ at $4^{\circ} \mathrm{C}$. The upper layer of the supernatant was taken and transferred to a new Eppendorf tube (Eppendorf AG). An equal volume of isopropanol was added into this new tube, the solution was mixed and rested on ice for $5 \mathrm{~min}$ and then centrifuged at $12,000 \mathrm{x} \mathrm{g}$ for $15 \mathrm{~min}$ at $4^{\circ} \mathrm{C}$. Following this, the supernatant was removed and the pellet dried with filter paper.
Ethanol $(75 \%, 1 \mathrm{ml})$ was added to wash the pellet, which was then centrifuged again at 7,500 $\mathrm{xg}$ for $5 \mathrm{~min}$ at $4^{\circ} \mathrm{C}$. Again, the supernatant was discarded and the pellet was dried at room temperature and then dissolved in $30 \mu 1$ of enzyme-free water. A spectrophotometer was utilized to measure the concentration and purity of the extracted RNA, which was then subjected to reverse transcription using a two-step reverse transcription kit (Takara, Tokyo, Japan). Messenger ribonucleic acids (mRNA) levels were measured using SYBR green (Toyobo, Osaka, Japan), with glyceraldehyde-3-phosphate dehydrogenase (GAPDH) expression used as an internal reference. FTO and GAPDH primers were synthesized by Shanghai Sangon Biotech Co., Ltd. (Shanghai, China). FTO upstream, 5'-ACTT GGCTCCCTTATCTGACC-3' and downstream, 5'-TGTGCA GTGTGAGAAAGGCTT-3'. GAPDH upstream, 5'-AGGTCG GTGTGAACGGATTTG-3' and downstream, 5'-TGTAGACC ATGTAGTTGAGGTCA-3'. The computational formula for mRNA relative expression level of each index was $2^{-\Delta \mathrm{Ct}}[\Delta \mathrm{Ct}=\mathrm{Ct}($ target gene $)-\mathrm{Ct}(\mathrm{GAPDH})]$.

Detection of serum FTO protein via western blot analysis. Since there was no available method to measure FTO protein expression in whole blood lymphocytes, whole blood samples for each study subject were collected before and after treatment. Partial serum taken after standing and centrifugation was diluted 10 times with phosphate-buffered saline (PBS) and an appropriate amount of protease inhibitor cocktail (Sigma-Aldrich, St. Louis, MO, USA) was added. A serum albumin/immunoglobulin removal kit (Shanghai Sangon Biotech) was employed to remove high-abundance proteins. A bicinchoninic acid kit (BCA; Beyotime Biotechnology Co., Ltd., Guangzhou, China) was used for protein concentration quantification. Protein samples $(40 \mu \mathrm{g})$ were added with loading buffer, then underwent electrophoresis using a $10 \%$ acrylamide gel and were transferred to a membrane. Membranes were incubated overnight with monoclonal anti-FTO antibodies (1:1,000; Cell Signaling Technology, Beverly, MA, USA). Ponceau total protein staining was used as a loading control (10), as many studies have shown that GAPDH and $\beta$-actin internal references were not accurate when analyzing serum samples. The relative content of the target protein was detected using enhanced chemiluminescent system (ECL; Merck Millipore, Billerica, MA, USA).

Statistical analysis. SPSS version 22.0 (SPSS, Inc., Chicago, IL, USA) statistical software was used to analyze experimental results. Chi-square test was utilized for enumeration data. Measurement data were expressed as mean \pm standard deviation (SD). Analysis of variance and paired t-test were applied for sample mean comparison. Spearman's rank correlation analysis was utilized for inter-indicator correlation analysis. $\mathrm{P}<0.05$ was considered to indicate a statistically significant difference.

\section{Results}

Comparisons of the patient general information among the three groups. There were no significant differences among the groups in age and sex $(p>0.05)$. Compared with those in the NC group, the BMIs, waist circumferences and hip 
Table I. General patient information comparison (mean \pm standard deviation).

\begin{tabular}{lccc}
\hline $\begin{array}{l}\text { Patient } \\
\text { information }\end{array}$ & $\begin{array}{c}\text { NC group } \\
(\mathrm{n}=60)\end{array}$ & $\begin{array}{c}\text { Mild T2DM } \\
\text { group }(\mathrm{n}=58)\end{array}$ & $\begin{array}{c}\text { Severe T2DM } \\
\text { group }(\mathrm{n}=52)\end{array}$ \\
\hline $\begin{array}{l}\text { Age (years) } \\
\text { Sex (male/female) }\end{array}$ & $\begin{array}{c}51.07 \pm 3.27 \\
27 / 23\end{array}$ & $50.34 \pm 4.20$ & $52.03 \pm 3.29$ \\
BMI $\left(\mathrm{kg} / \mathrm{m}^{2}\right)$ & $23.45 \pm 4.08$ & $26.83 \pm 2.54^{\mathrm{a}}$ & $28.23 \pm 3.50^{\mathrm{b}, \mathrm{c}}$ \\
$\begin{array}{l}\text { Waist circumference } \\
(\mathrm{cm})\end{array}$ & $84.32 \pm 7.89$ & $87.89 \pm 5.76^{\mathrm{a}}$ & $105.32 \pm 6.32^{\mathrm{a}, \mathrm{c}}$ \\
$\begin{array}{l}\text { Hip circumference } \\
(\mathrm{cm})\end{array}$ & $90.67 \pm 5.65$ & $93.58 \pm 7.34^{\mathrm{a}}$ & $100.01 \pm 8.44^{\mathrm{b}, \mathrm{c}}$ \\
\end{tabular}

${ }^{\mathrm{a}} \mathrm{p}<0.05,{ }^{\mathrm{b}} \mathrm{p}<0.01$ vs. $\mathrm{NC}$ group; ${ }^{\mathrm{p}} \mathrm{p}<0.05$ vs. mild T2DM group. NC, negative control; T2DM, type 2 diabetes mellitus; BMI, body mass index.

Table II. Patient blood glucose-related indicator values (mean \pm standard deviation).

\begin{tabular}{lccc}
\hline Indexes & $\begin{array}{c}\text { NC group } \\
(\mathrm{n}=60)\end{array}$ & $\begin{array}{c}\text { Mild T2DM } \\
\text { group }(\mathrm{n}=58)\end{array}$ & $\begin{array}{c}\text { Severe T2DM } \\
\text { group }(\mathrm{n}=52)\end{array}$ \\
\hline FPG (mmol/l) & $6.67 \pm 2.03$ & $7.89 \pm 2.89^{\mathrm{a}}$ & $8.95 \pm 3.04^{\mathrm{a}, \mathrm{c}}$ \\
FINs $(\mathrm{mmol} / \mathrm{l})$ & $7.34 \pm 4.13$ & $9.04 \pm 4.76^{\mathrm{a}}$ & $13.46 \pm 6.34^{\mathrm{b}, \mathrm{c}}$ \\
HOMA-IR & $1.98 \pm 1.02$ & $3.03 \pm 1.67^{\mathrm{a}}$ & $4.60 \pm 2.01^{\mathrm{b}, \mathrm{c}}$ \\
FCP (mmol/l) & $342 \pm 148.67$ & $528 \pm 168.05^{\mathrm{b}}$ & $685 \pm 186.33^{\mathrm{a}, \mathrm{c}}$ \\
HbA1c $(\%)$ & $7.03 \pm 2.58$ & $7.86 \pm 3.02^{\mathrm{a}}$ & $9.28 \pm 3.40^{\mathrm{a}, \mathrm{c}}$ \\
\hline
\end{tabular}

${ }^{\mathrm{a}} \mathrm{p}<0.05,{ }^{\mathrm{b}} \mathrm{p}<0.01 \mathrm{vs}$. NC group; ${ }^{\mathrm{p}} \mathrm{p}<0.05$ vs. mild T2DM group. T2DM, type 2 diabetes mellitus; FPG, fasting plasma glucose; FCP, fasting C-peptide; HbAlc, glycosylated hemoglobin; FINs, fasting insulin; HOMA-IR, homeostasis model assessment of insulin resistance.

circumferences of the T2DM groups were elevated $(\mathrm{p}<0.05)$. Compared with the mild T2DM group, BMI, waist circumference and hip circumference in the severe T2DM group were increased $(\mathrm{p}<0.05$; Table I).

Lymphocyte FTO gene expression levels. FTO gene expression levels in the mild T2DM group $(\mathrm{p}<0.01)$ and severe T2DM group $(p<0.001)$ were significantly increased relative to the $\mathrm{NC}$ group. FTO gene levels in the severe T2DM group were higher than in the mild T2DM group ( $<<0.05 ;$ Fig. 1).

FTO protein content in patient serum. Serum FTO protein levels were consistent with gene levels determined via RT-PCR, with FTO significantly increased in the T2DM groups (Fig. 2).

Blood glucose-related indicators (FPG, FCP, HbAlc, FINs and HOMA-IR) in normal and T2DM individuals. FPG, FINs, HOMA-IR, FCP and HbA1c values in the two T2DM groups were higher than in the $\mathrm{NC}$ group $(\mathrm{p}<0.05)$. Moreover, there were significant differences between the severe T2DM group and the mild T2DM group $(\mathrm{p}<0.05$; Table II).

Post-treatment changes in severe T2DM patient blood glucose indices (FPG, FCP, HbAlc and FINs). We tested the blood

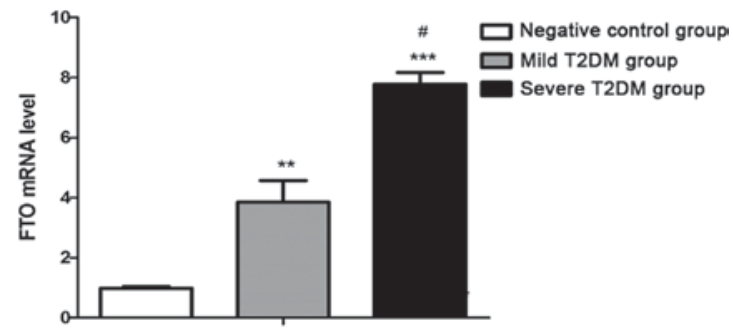

Figure 1. FTO mRNA levels in peripheral blood lymphocytes detected via RT-PCR. FTO gene expression levels in the mild T2DM and severe T2DM group were significantly increased $\left({ }^{* *} \mathrm{p}<0.01,{ }^{* * *} \mathrm{p}<0.001\right)$ vs. $\mathrm{NC}$ group levels. FTO gene levels in the severe T2DM group were higher than in the mild T2DM group $\left({ }^{\#} \mathrm{p}<0.05\right)$. FTO, fat mass and obesity-associated gene; T2DM, type 2 diabetes mellitus; $\mathrm{NC}$, normal control.

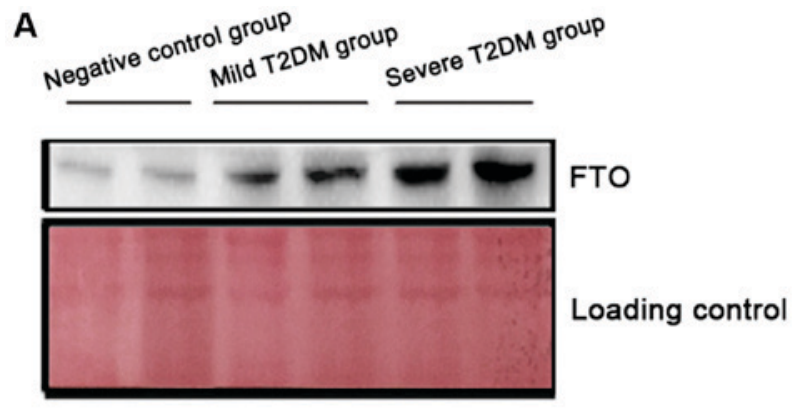

B

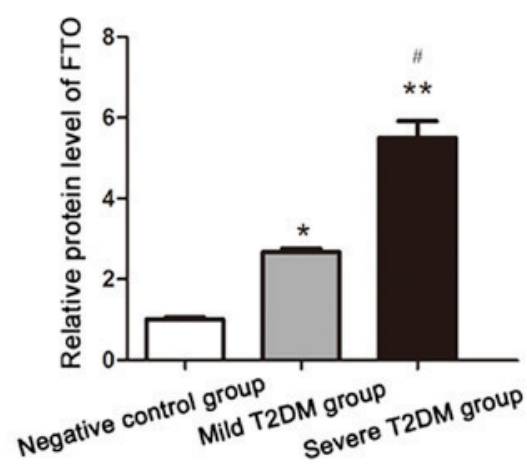

Figure 2. Patient serum FTO protein levels detected via western blot analysis. FTO protein levels in the mild and severe T2DM groups were significantly elevated relative to the NC group ( $\left.{ }^{*} \mathrm{p}<0.05,{ }^{* *} \mathrm{p}<0.001\right)$. FTO protein levels in the severe group was higher than in the mild group $\left({ }^{\#} \mathrm{p}<0.05\right)$. FTO, fat mass and obesity-associated gene; T2DM, type 2 diabetes mellitus; NC, normal control.

glucose-related indicators of the 52 patients with severe T2DM after they received 12 weeks of treatment. FPG, FCP, HbAlc, FINs and HOMA-IR values after treatment were observably decreased when compared with those before treatment $(\mathrm{p}<0.05$; Table III).

FTO protein expression in severe T2DM patients before and after treatment. We further explored the relationship between FTO and T2DM severity. FTO protein levels after treatment was significantly reduced relative to before treatment (Fig. 3).

Correlation between of FTO protein expression and other T2DM indicators. Spearman's rank correlation analysis 
Table III. Severe T2DM patient BMI and the blood glucose indices before and after treatment (mean \pm standard deviation).

\begin{tabular}{lcccc}
\hline Indexes & $\begin{array}{c}\text { Before } \\
\text { treatment }\end{array}$ & $\begin{array}{c}\text { After } \\
\text { treatment }\end{array}$ & t-value & P-value \\
\hline BMI $\left(\mathrm{kg} / \mathrm{m}^{2}\right)$ & $28.23 \pm 3.50$ & $25.97 \pm 4.32^{\mathrm{a}}$ & 5.36 & 0.031 \\
FPG $(\mathrm{mmol} / \mathrm{l})$ & $9.95 \pm 3.04$ & $8.12 \pm 3.56^{\mathrm{a}}$ & 4.36 & 0.047 \\
FINs $(\mathrm{mmol} / \mathrm{l})$ & $13.46 \pm 6.34$ & $10.74 \pm 5.32^{\mathrm{a}}$ & 3.78 & 0.026 \\
HOMA-IR & $4.60 \pm 2.01$ & $3.35 \pm 2.36^{\mathrm{a}}$ & 3.95 & 0.017 \\
FCP $(\mathrm{mmol} / \mathrm{l})$ & $685 \pm 186.33$ & $536 \pm 169.30^{\mathrm{b}}$ & 5.80 & 0.0073 \\
HbA1c $(\%)$ & $9.28 \pm 3.40$ & $8.04 \pm 2.78^{\mathrm{a}}$ & 4.05 & 0.035
\end{tabular}

${ }^{\mathrm{a}} \mathrm{p}<0.05,{ }^{\mathrm{b}} \mathrm{p}<0.01$ vs. before treatment. T2DM, type 2 diabetes mellitus; BMI, body mass index; FPG, fasting plasma glucose; FINs, fasting insulin; HOMA-IR, homeostasis model assessment of insulin resistance; FCP, fasting C-peptide; HbA1c, glycosylated hemoglobin.

Table IV. Analysis of the correlation between FTO and T2DM indicators.

\begin{tabular}{lrr}
\hline & \multicolumn{2}{c}{ FTO protein } \\
\cline { 2 - 3 } Parameters & r value & P-value \\
\hline Age (years) & 0.054 & 0.072 \\
Sex (male/female) & 0.032 & 0.065 \\
BMI $\left(\mathrm{kg} / \mathrm{m}^{2}\right)$ & 0.648 & 0.002 \\
Waist circumference $(\mathrm{cm})$ & 0.563 & 0.046 \\
Hip circumference $(\mathrm{cm})$ & 0.572 & 0.041 \\
FPG $(\mathrm{mmol} / \mathrm{l})$ & 0.731 & 0.008 \\
FINs $(\mathrm{mmol} / \mathrm{l})$ & 0.640 & $<0.001$ \\
HOMA-IR & 0.752 & $<0.001$ \\
FCP $(\mathrm{mmol} / \mathrm{l})$ & 0.693 & 0.003 \\
HbA1c $(\%)$ & 0.728 & $<0.001$ \\
\hline
\end{tabular}

FTO, fat mass and obesity-associated gene; T2DM, type 2 diabetes mellitus; BMI, body mass index; FPG, fasting plasma glucose; FINs, fasting insulin HOMA-IR, homeostasis model assessment of insulin resistance; FCP, fasting C-peptide; HbA1c, glycosylated hemoglobin.

showed that FTO protein expression was not associated with age or gender, but it was positively correlated with BMI, waist circumference, hip circumference, FPG, FCP, HbA1c, FINs and HOMA-IR $(\mathrm{p}<0.05$; Table IV).

\section{Discussion}

Diabetes is a highly prevalent and serious chronic debilitating disease and has been reported as the fourth leading cause of death in Europe (11). T2DM is characterized by progressive insulin resistance and $\beta$-cell dysfunction and usually inactivity and weight are elevated with an increase in age or food intake (12). A large number of studies have shown that $\beta$-cell dysfunction, oxidative stress and excessive fatty acids form the pathological basis of diabetes (13). However, it is non-negligible that T2DM also has significant genetic heterogeneity and now a variety of mutations have been identified in insulin genes,
A

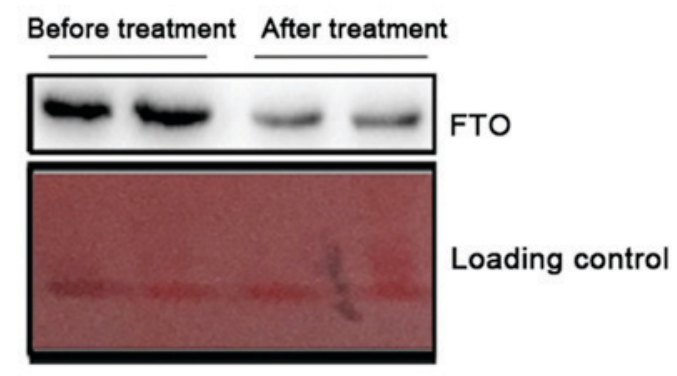

B

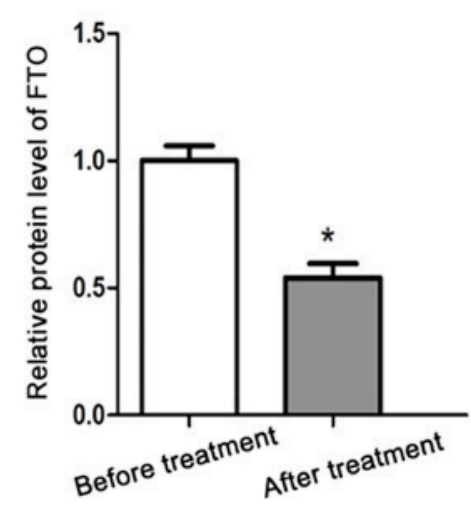

Figure 3. Serum FTO protein levels detected via western blot analysis Compared with before-treatment values, FTO protein levels were significantly lower after treatment $\left({ }^{*} \mathrm{p}<0.05\right)$. FTO, fat mass and obesity-associated gene.

insulin receptor genes, glucokinase genes and mitochondrial genes $(14,15)$.

FTO-induced obesity and increased BMI values play important roles in the initiation and progression of T2DM (16). However, people know very little about the specific molecular mechanisms of how the FTO gene regulates BMI and induces T2DM. In accordance with sequence homology analysis, the predicted coding protein of FTO gene is 2-ketoglutarate-dependent demethylase (17), which affects the transcription of various metabolism-related genes by influencing epigenetic regulatory mechanisms such as nucleic acid demethylation. Guo et al (18) found that the FTO gene is enriched in the hepatocytes of patients with non-alcoholic fatty liver and promotes hepatocyte oxidative stress and fat deposition. Oxidative stress can activate a variety of intracellular signal pathways directly leading to cell and tissue injury and thus aggravating and complicating diabetes $(19,20)$. Some recent studies have indicated that FTO gene polymorphisms are associated with energy intake and involved in the decomposition of fat $(21,22)$.

In the present study, we found that FTO protein was highly expressed in patients with T2DM and was significantly higher in those with severe T2DM. Correlation analysis showed that FTO protein level was not correlated with age or gender, but was significantly associated with waist circumference, hip circumference, BMI and blood glucose indices (FPG, FCP, HbA1c, FINs). After 12 weeks of treatment, blood glucose indice values and FTO expression levels were both significantly decreased in patients with severe T2DM. In conclusion, we have found that the expression of the obesity gene FTO increases with T2DM severity. We hope that the FTO gene 
can provide a reference value for the diagnosis and treatment of $\mathrm{T} 2 \mathrm{DM}$ in the future.

\section{References}

1. Dandona P, Aljada A and Bandyopadhyay A: Inflammation: The link between insulin resistance, obesity and diabetes. Trends Immunol 25: 4-7, 2004

2. Sheehan MT: Current therapeutic options in type 2 diabetes mellitus: A practical approach. Clin Med Res 1: 189-200, 2003.

3. Ballantyne GH, Gumbs A and Modlin IM: Changes in insulin resistance following bariatric surgery and the adipoinsular axis: Role of the adipocytokines, leptin, adiponectin and resistin. Obes Surg 15: 692-699, 2005.

4. Imamura $M$ and Maeda S: Genetics of type 2 diabetes: The GWAS era and future perspectives (Review). Endocr J 58: 723-739, 2011.

5. Loos RJ and Yeo GS: The bigger picture of FTO: The first GWASidentified obesity gene. Nat Rev Endocrinol 10: 51-61, 2014.

6. Claussnitzer M, Dankel SN, Kim KH, Quon G, Meuleman W, Haugen C, Glunk V, Sousa IS, Beaudry JL, Puviindran V, et al: FTO obesity variant circuitry and adipocyte browning in humans. N Engl J Med 373: 895-907, 2015.

7. Hinney A, Nguyen TT, Scherag A, Friedel S, Brönner G Müller TD, Grallert H, Illig T, Wichmann HE, Rief W, et al: Genome wide association (GWA) study for early onset extreme obesity supports the role of fat mass and obesity associated gene (FTO) variants. PLoS One 2: e1361, 2007.

8. Wang J, Mei H, Chen W, Jiang Y, Sun W, Li F, Fu Q and Jiang F: Study of eight GWAS-identified common variants for association with obesity-related indices in Chinese children at puberty. Int J Obes 36: 542-547, 2012

9. Abarin T, Yan Wu Y, Warrington N, Lye S, Pennell C and Briollais L: The impact of breastfeeding on FTO-related BMI growth trajectories: An application to the Raine pregnancy cohort study. Int J Epidemiol 41: 1650-1660, 2012.

10. Kunji ER, Aleksandrova A, King MS, Majd H, Ashton VL, Cerson E, Springett R, Kibalchenko M, Tavoulari S, Crichton PG, et al: The transport mechanism of the mitochondrial ADP/ATP carrier. Biochim Biophys Acta 1863: 2379-2393, 2016

11. Rydén L, Standl E, Bartnik M, Van den Berghe G, Betteridge J, de Boer MJ, Cosentino F, Jönsson B, Laakso M, Malmberg K, et al; Task Force on Diabetes and Cardiovascular Diseases of the European Society of Cardiology (ESC); European Association for the Study of Diabetes (EASD): Guidelines on diabetes, prediabetes, and cardiovascular diseases: Executive summary. Eur Heart J 28: 88-136, 2007.

12. Ribola FA, Cançado FB, Schoueri JH, De Toni VF, Medeiros VH and Feder D: Effects of SGLT2 inhibitors on weight loss in patients with type 2 diabetes mellitus. Eur Rev Med Pharmacol Sci 21: 199-211, 2017.
13. Szulinska M, Gibas-Dorna M, Miller-Kasprzak E, Suliburska J, Miczke A, Walczak-Gałezewska M, Stelmach-Mardas M, Walkowiak J and Bogdanski P: Spirulina maxima improves insulin sensitivity, lipid profile, and total antioxidant status in obese patients with well-treated hypertension: A randomized double-blind placebo-controlled study. Eur Rev Med Pharmacol Sci 21: 2473-2481, 2017.

14. Miyazaki Y, Mahankali A and Matsuda M: Effect of pioglitazone on abdominal fat distribution and insulin sensitivity in patients with type 2 diabetes mellitus (T2DM). Diabetes 5: 299, 2000

15. Bhat A, Koul A, Rai E, Sharma S, Dhar MK and Bamezai RN: PGC-1 $\alpha$ Thr394Thr and Gly482Ser variants are significantly associated with T2DM in two North Indian populations: A replicate case-control study. Hum Genet 121: 609-614, 2007.

16. Freathy RM, Timpson NJ, Lawlor DA, Pouta A, Ben-Shlomo Y, Ruokonen A, Ebrahim S, Shields B, Zeggini E, Weedon MN, et al: Common variation in the FTO gene alters diabetes-related metabolic traits to the extent expected given its effect on BMI. Diabetes 57: 1419-1426, 2008.

17. Gerken T, Girard CA, Tung YC, Webby CJ, Saudek V, Hewitson KS, Yeo GS, McDonough MA, Cunliffe S, McNeill LA, et al: The obesity-associated FTO gene encodes a 2-oxoglutarate-dependent nucleic acid demethylase. Science 318: $1469-1472,2007$

18. Guo J, Ren W, Li A, Ding Y, Guo W, Su D, Hu C, Xu K, Chen H, $\mathrm{Xu} \mathrm{X}$, et al: Fat mass and obesity-associated gene enhances oxidative stress and lipogenesis in nonalcoholic fatty liver disease. Dig Dis Sci 58: 1004-1009, 2013.

19. Robertson RP, Harmon J, Tran PO, Tanaka Y and Takahashi H: Glucose toxicity in $\beta$-cells: Type 2 diabetes, good radicals gone bad, and the glutathione connection. Diabetes 52: 581-587, 2003.

20. Kajimoto $\mathrm{Y}$ and Kaneto $\mathrm{H}$ : Role of oxidative stress in pancreatic $\beta$-cell dysfunction. Ann N Y Acad Sci 1011: 168-176, 2004

21. Speakman JR, Rance KA and Johnstone AM: Polymorphisms of the FTO gene are associated with variation in energy intake, but not energy expenditure. Obesity (Silver Spring) 16: 1961-1965, 2008

22. Wåhlén K, Sjölin E and Hoffstedt J: The common rs9939609 gene variant of the fat mass- and obesity-associated gene FTO is related to fat cell lipolysis. J Lipid Res 49: 607-611, 2008.

This work is licensed under a Creative Commons Attribution-NonCommercial-NoDerivatives 4.0 International (CC BY-NC-ND 4.0) License. 